Case Reports in
Gastroenterology
Case Rep Gastroenterol 2020;14:504-509

DOI: $10.1159 / 000508860$

Published online: October 22, 2020 (c) 2020 The Author(s)

Published by S. Karger AG, Basel www.karger.com/crg

This article is licensed under the Creative Commons Attribution-NonCommercial 4.0 International License (CC BY-NC) (http://www.karger.com/Services/OpenAccessLicense). Usage and distribution for commercial purposes requires written permission.

\title{
Progressive Primary Appendiceal Crohn's Disease in a 21-Year-old Female
}

\author{
Cullen Roberts $^{a}$ Jason L. Hornick ${ }^{b}$ Vanessa Mitsialis ${ }^{c} \quad$ James $Y_{0 o^{a}}$ \\ aDepartment of Surgery, Brigham and Women's Hospital, Boston, MA, USA; \\ bepartment of Pathology, Brigham and Women's Hospital, Boston, MA, USA; \\ 'Department of Medicine, Brigham and Women's Hospital, Boston, MA, USA
}

\section{Keywords}

Crohn's disease · Appendicitis · Appendectomy

\begin{abstract}
Crohn's disease is an inflammatory bowel disorder that can affect any portion of the gastrointestinal tract, most commonly the terminal ileum near the ileocecal valve. Crohn's disease can be characterized by transmural inflammation and deep fissuring ulcers that predispose to fistula formation and "skip" lesions separated by normal segments of bowel. While often affecting the terminal ileum near the ileocecal valve, Crohn's disease presenting primarily in the appendix is a rare entity. In part due to its low prevalence, cases of appendiceal Crohn's disease can be confused for acute, non-Crohn's-related appendicitis on initial presentation. Although there are published cases of primary appendiceal Crohn's disease in the medical literature, in most cases the diagnosis is made retrospectively following appendectomy for presumed appendicitis. We report on a case of Crohn's disease that was diagnosed pre-operatively, primarily involved the appendix, and which progressed radiographically despite medical therapy and resolution of clinical symptoms. Unique management issues related to this case include the appropriateness of systemic therapy for disease isolated to the appendix, an inability to endoscopically obtain tissue for a definitive diagnosis, and the decision to proceed with surgery in an asymptomatic patient with progressive disease on imaging. Intraoperatively, the appendix was severely inflamed and densely adherent to the left pelvic side wall and adjacent to the left ovary and fallopian tube. A laparoscopic appendectomy was performed. Pathology
\end{abstract}




\section{Case Reports in Gastroenterology}

Case Rep Gastroenterol 2020;14:504-509

DOI: $10.1159 / 000508860$

(c) 2020 The Author(s). Published by S. Karger AG, Basel www.karger.com/crg

Roberts et al.: Progressive Primary Appendiceal Crohn's Disease in a 21-Year-old Female

demonstrated acute appendicitis as well as marked mural chronic inflammation and epithelioid granulomas, consistent with Crohn's disease. Surgical resection may be the most appropriate treatment for Crohn's disease primarily involving the appendix, obviating the need for systemic therapy and minimizing the risk for appendiceal perforation and fistula formation.

(C) 2020 The Author(s)

Published by S. Karger AG, Basel

\section{Case Presentation}

The patient is a 21-year-old female with no significant past medical history. Six months prior to her evaluation for surgery, the patient presented to her primary care physician with symptoms of severe, intermittent bilateral lower quadrant abdominal pain that would last for 1-2 weeks between episodes. She underwent a computed tomography scan of the abdomen and pelvis that showed moderate wall thickening of the terminal ileum and cecum, as well as a linear structure seen posterior to the cecum with a diameter of $1.2 \mathrm{~cm}$, representing a dilated appendix. The patient subsequently underwent a colonoscopy that was notable for mild terminal ileal and cecal inflammation (Fig. 1), with biopsies showing active ileitis and chronic active colitis with non-necrotizing epithelioid granulomas. The patient was prescribed a 2month course of budesonide, which she completed initially without improvement in her symptoms. After completion of her budesonide course, the patient underwent blood testing notable for persistent evidence of inflammation including an elevated ESR and CRP of 25 and 9.7, respectively, but no other lab abnormalities, including a normal WBC count and negative tuberculosis testing.

Four months after her original computed tomography scan, an MRI enterography demonstrated a normal-appearing terminal ileum and cecum, and an inflamed blind-ended tubular structure measuring up to $1.3 \mathrm{~cm}$ in diameter (Fig. 2) with wall thickening and mural enhancement, arising from the cecum and consistent with acute uncomplicated appendicitis. Although at that time the patient was not experiencing abdominal pain, given the imaging findings, she was prescribed a 14-day course of ciprofloxacin and flagyl. A repeat MRI enterography following completion of the antibiotics again showed an inflamed appendix with slightly decreased wall thickening but with increased distention.

Given the worsening radiographic appearance of the appendix that raised concerns about impending perforation, along with the lack of a tissue diagnosis, a laparoscopic appendectomy was recommended. At the time of surgery, a severely inflamed appendix was visible in the pelvis, and was found to be densely adherent to the left pelvic sidewall immediately adjacent to the left ovary and fallopian tube (online suppl. video; for all online suppl. material, see www.karger.com/doi/10.1159/000508860). The left ovary and fallopian tube were carefully dissected away from the appendix, the appendix was separated from the left pelvic sidewall, and an appendectomy was performed. The entire appendix appeared inflamed, but the base of the appendix and the adjacent cecum appeared normal. The patient's postoperative course was uncomplicated.

The resected specimen was examined grossly in pathology (Fig. 3a) and appeared inflamed but soft, without evidence of masses. The appendix had a maximal diameter of $1.9 \mathrm{~cm}$ with no masses or lesions identified. The luminal diameter measured up to $0.8 \mathrm{~cm}$ with an average wall thickness of $0.5 \mathrm{~cm}$. Histologically (Fig. 3b), the appendix demonstrated acute appendicitis, marked mucosal chronic inflammation with crypt architectural distortion, transmural lymphoid aggregates, and epithelioid granulomas, consistent with Crohn's appendicitis. 


\section{Case Reports in Gastroenterology}

The patient has done well postoperatively without recurrence of abdominal pain or loose stools, on no medication.

\section{Discussion}

Appendiceal Crohn's disease is a recognized entity, with multiple case reports detailing patients with involvement of the appendix [1-3]. Despite the well-documented existence of this disease entity, cases of appendiceal Crohn's disease are often accompanied by ileal and/or colonic mucosal inflammation that can present with symptoms of enteritis or abdominal pain. Crohn's disease presenting solely with symptoms of appendicitis due to appendiceal involvement is exceedingly rare. One review of all Crohn's disease diagnoses made at a single hospital over a 20-year span found the rate of Crohn's disease confined to the appendix to be $0.2 \%$ [4], typically identified following an appendectomy for what was believed to be routine appendicitis. A review of all appendectomy specimens from over 5 years at a single hospital found that only approximately $0.5 \%$ showed features of Crohn's disease on postoperative pathology [2]. Given the rarity of the diagnosis, it is very uncommon to diagnose appendiceal Crohn's disease preoperatively. Medical management of isolated appendiceal Crohn's disease is challenging because the lumen of the appendix is not accessible for a confirmatory tissue diagnosis [5] or for topical therapy, and systemic therapy is contraindicated for such isolated disease. In the case of our patient, our suspicion for appendiceal involvement of Crohn's disease was raised by the atypical course of appendicitis in the patient (persistent radiographic findings of appendicitis over the course of a 5-month period with intermittent bouts of severe pain) along with mild mucosal findings of Crohn's disease in the surrounding ileal/colonic mucosa. In terms of surgical management for patients with appendiceal Crohn's, involvement of the base of the appendix or the cecum may alter the extent of surgical resection, highlighting the importance of a colonoscopy prior to elective surgical intervention. We elected to perform an appendectomy without ileocolic resection given the normal external appearance of the base of the appendix, along with the preoperative endoscopic evaluation that demonstrated minimal mucosal involvement. An intraoperative colonoscopy can be helpful to assess involvement at the appendiceal orifice if a more extensive resection is being considered. Despite the propensity for fistula formation in Crohn's disease, fistula rates following an appendectomy for appendiceal Crohn's disease appear to be low [4]. In this patient, the intraoperative findings were notable for dense adhesions of the inflamed appendix near the left ovary and fallopian tube, raising concerns about an impending fistula in the absence of surgical intervention.

In conclusion, appendiceal Crohn's disease is a rare entity that provides both a diagnostic and management dilemma when diagnosed preoperatively. Challenges include the inaccessibility of the appendix for diagnostic testing as well as topical therapy, and the role of surgery given the propensity for fistula formation and perforation. Fortunately, these cases can be safely treated by laparoscopic appendectomy if the appendiceal base and nearby cecum are normal in appearance.

\section{Acknowledgements}

No funding sources were used in the preparation of this manuscript. 


\section{Case Reports in Gastroenterology}

\section{Statement of Ethics}

Written informed consent was obtained from the patient for publication of this Case report and any accompanying images. A copy of the written consent is available for review by the Editor of this journal.

\section{Conflict of Interest Statement}

The authors declare that they have no competing interests.

\section{Author Contributions}

C.R. was involved in drafting and revising the manuscript, conception and design, and final approval. J.L.H. was involved in image collection and manuscript review. V.M. was involved in image collection and manuscript review. J.Y. was involved in drafting and revising the manuscript, conception and design, and final approval.

\section{References}

1 Gnanaselvam P, Weerakoon DN, Wijayasuriya WAM, Mohottala VS, Sinhakumara BMES, Jayarajah U, et al. Isolated Crohn's Disease of the Appendix Presenting as Acute Appendicitis in a 60-Year-Old South Asian Female: A Case Report, Review of Literature, and Follow-Up Recommendations. Case Rep Surg. 2019 Oct;2019:5285417.

2 Han H, Kim H, Rehman A, Jang SM, Paik SS. Appendiceal Crohn's disease clinically presenting as acute appendicitis. World J Clin Cases. 2014 Dec;2(12):888-92.

3 Yang SS, Gibson P, McCaughey RS, Arcari FA, Bernstein J. Primary Crohn's disease of the appendix: report of 14 cases and review of the literature. Ann Surg. 1979 Mar;189(3):334-9.

4 Prieto-Nieto I, Perez-Robledo JP, Hardisson D, Rodriguez-Montes JA, Larrauri-Martinez J, Garcia-SanchoMartin L. Crohn's disease limited to the appendix [Internet]. Am J Surg. 2001 Nov;182(5):531-3. [cited 2020 Apr 1] Available from: http://www.ncbi.nlm.nih.gov/pubmed/11754865.

5 Murdock T, Lim N, Zenali M. Lymphangitic spread from the appendiceal adenocarcinoma to the ileocecal valve, mimicking Crohn's disease. World J Gastroenterol. 2015 Feb;21(7):2206-9.

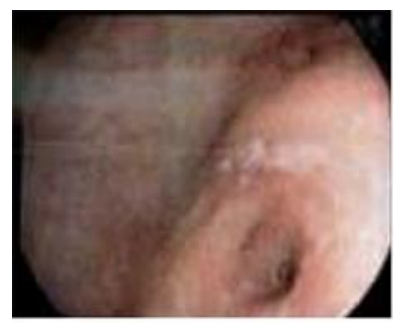

Appendiceal orifice with Erythematous mucosa

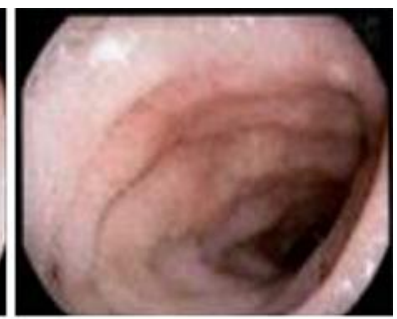

Terminal ileum with erosions

Fig. 1. Endoscopic appearance of the appendiceal orifice and the terminal ileum. 
Case Reports in Gastroenterology
Case Rep Gastroenterol 2020;14:504-509

DOI: 10.1159/000508860

(c) 2020 The Author(s). Published by S. Karger AG, Basel www.karger.com/crg

Roberts et al.: Progressive Primary Appendiceal Crohn's Disease in a 21-Year-old Female

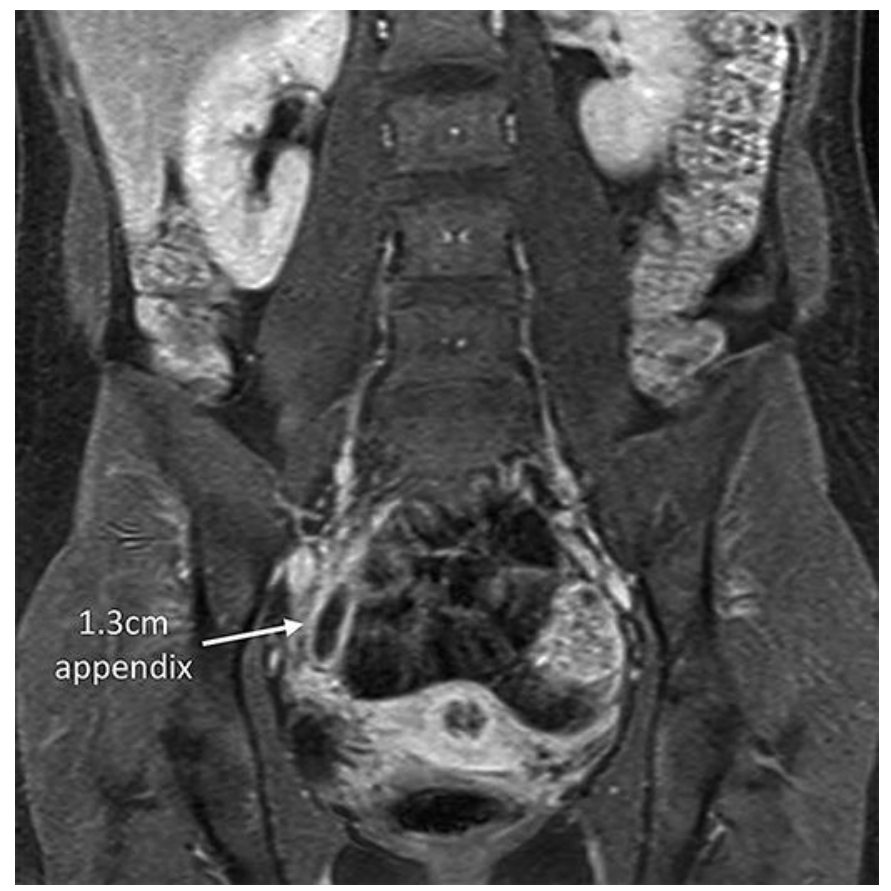

Fig. 2. Preoperative magnetic resonance imaging enterography. Preoperative imaging demonstrating a dilated appendix abutting the left pelvic sidewall. 
Case Reports in Gastroenterology
Case Rep Gastroenterol 2020;14:504-509

DOI: $10.1159 / 000508860$

(c) 2020 The Author(s). Published by S. Karger AG, Basel www.karger.com/crg

Roberts et al.: Progressive Primary Appendiceal Crohn's Disease in a 21-Year-old Female
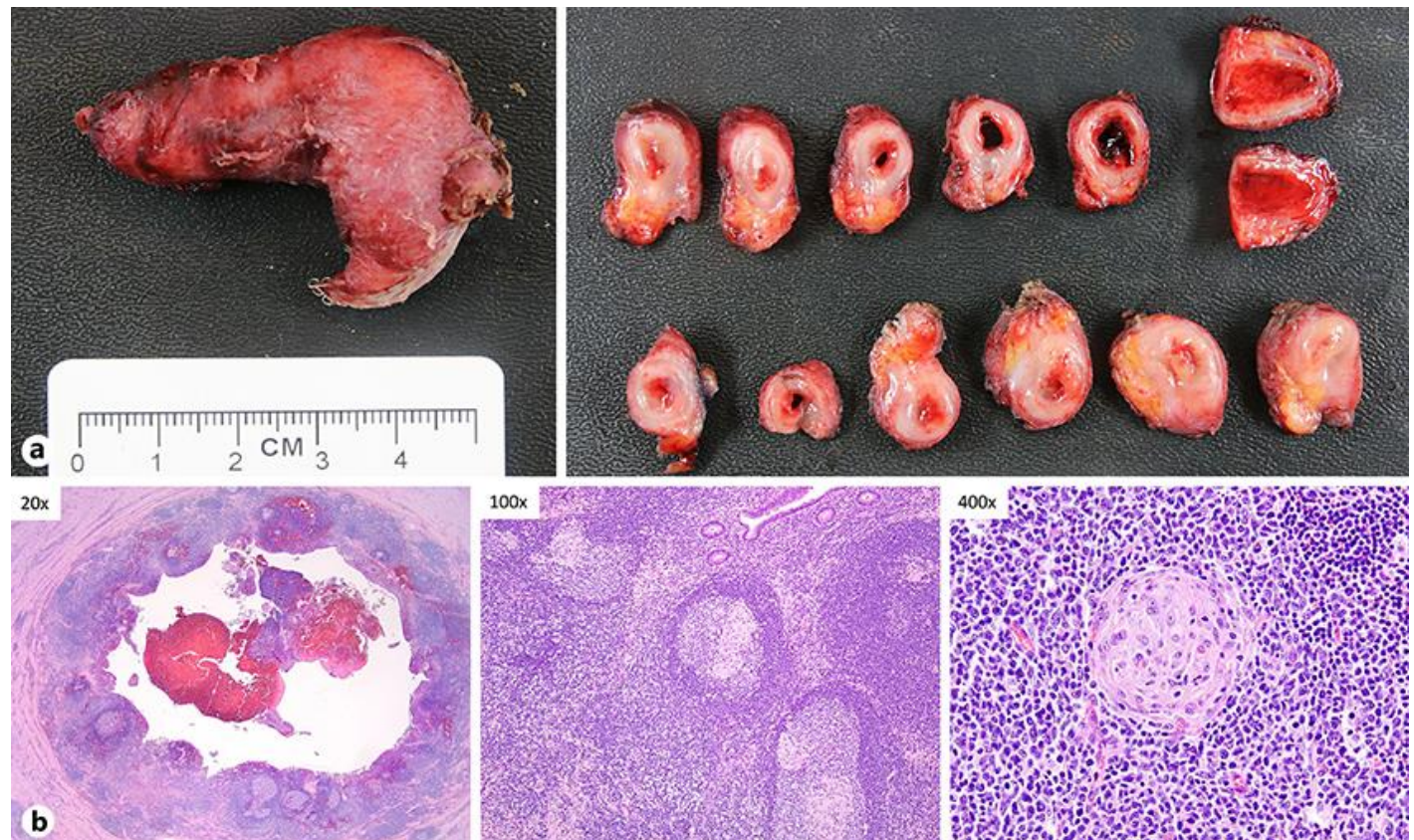

Fig. 3. Gross and histologic evaluation of the resected specimen. a The appendix is swollen with a shaggy serosal appearance (left); cross sections demonstrate a thickened wall, dilated lumen, and luminal hemorrhage. b Histologic findings include marked mucosal chronic inflammation (left; original magnification $\times 20$ ), mucosal lymphoid aggregates with crypt architectural distortion (middle; original magnification $\times 100$ ), and epithelioid granulomas (right; original magnification $\times 400$ ). 